\title{
Comprehensively addressing postpartum maternal health: a content and image review of commercially available mobile health apps
}

Laura Tucker ${ }^{1 *}$, Alan Cuevas Villagomez ${ }^{1}$ and Tamar Krishnamurti ${ }^{2}$

\begin{abstract}
Background: The United States is currently facing a maternal morbidity and mortality crisis, with the highest rates of any resource-rich nation. In efforts to address this, new guidelines for postpartum care suggest that mobile health (mHealth) apps can help provide complementary clinical support for new mothers during the postpartum period. However, to date no study has evaluated the quality of existing mHealth tools targeted to this time period in terms of sufficiency of maternal health information, inclusivity of people of color, and app usability.

Methods: Preferred Reporting Items for Systematic Reviews and Meta-Analyses (PRISMA) standards were used to review the peripartum apps from the Apple and Google Play stores in either the Health/Fitness, Medical, or Education categories. Apps were evaluated for extent and quality of maternal health information and inclusivity of people of color using an a priori coding scheme. App usability was evaluated using the Mobile Application Rating Scale (MARS) score.

Results: Of the 301 apps from the Apple and Google Play stores, 25 met criteria for final evaluation. Of the 30 maternal health topics coded for, the median number addressed by apps was 19.5 (65\%). Peripartum behaviors were more frequently addressed than peripartum outpatient care topics and peripartum acute health risks. The coverage of maternal health information and inclusivity of people of color in app imagery both correlated positively with the MARS usability score of the app. Only 8 apps (32\%) portrayed greater than $24 \%$ images of people of colorthe percent of non-white Americans according to 2019 census estimates. There was no correlation between MARS usability score and number of app users, as estimated by number of ratings for the app available on the app store. In addition, apps with evidence-based maternal health information had greater MARS engagement, information, and aesthetics scores. However, presence of evidence-based information did not correlate with greater numbers of app users.

(Continued on next page)
\end{abstract}

\footnotetext{
* Correspondence: lat98@pitt.edu

${ }^{1}$ University of Pittsburgh School of Medicine, 3550 Terrace St, Pittsburgh, PA

15213, USA

Full list of author information is available at the end of the article
}

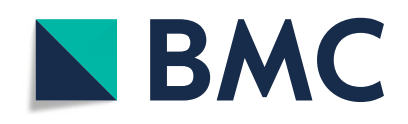

(- The Author(s). 2021 Open Access This article is licensed under a Creative Commons Attribution 4.0 International License, which permits use, sharing, adaptation, distribution and reproduction in any medium or format, as long as you give appropriate credit to the original author(s) and the source, provide a link to the Creative Commons licence, and indicate if changes were made. The images or other third party material in this article are included in the article's Creative Commons licence, unless indicated otherwise in a credit line to the material. If material is not included in the article's Creative Commons licence and your intended use is not permitted by statutory regulation or exceeds the permitted use, you will need to obtain permission directly from the copyright holder. To view a copy of this licence, visit http://creativecommons.org/licenses/by/4.0/. The Creative Commons Public Domain Dedication waiver (http://creativecommons.org/publicdomain/zero/1.0/) applies to the data made available in this article, unless otherwise stated in a credit line to the data. 
(Continued from previous page)

Conclusions: Current commercially available peripartum apps range widely in quality. Overall current app offerings generally do not provide adequate maternal health information and are not optimally accessible to the target users in terms of inclusivity of women of color or app usability. Apps delivering evidence-based information and more usable design are more likely to meet these standards but are not more likely to be downloaded by users.

Keywords: Pregnancy, Postpartum, Peripartum, Maternal health, mHealth, Mobile health, Digital health, Maternal morbidity, Health education, Health disparity, Mobile apps

\section{Background}

The United States is currently facing a maternal morbidity and mortality crisis. The maternal mortality rate has more than doubled since 1990, and currently stands at 17.4 deaths per 100,000 live births-- the highest of any resource-rich nation [1]. The leading documented causes of maternal death are infection, hemorrhage, cardiomyopathy, other cardiovascular conditions, pulmonary embolism, stroke, hypertensive disorders, and amniotic fluid embolism [2]. Newly emerging data also suggests that psychosocial risks, such as intimate partner violence (IPV) and depression-induced suicide, may also play a key role in maternal mortality and morbidity occurring up to a year postpartum [3, 4]. Furthermore, an additional 60,000 U.S. women experience severe maternal morbidity each year [5]. Pregnancy-related maternal mortality and morbidity is disproportionately high among women of color whereby non-Hispanic Black women are more than 3 times more likely to experience pregnancy-related death than non-Hispanic white women [6-8]. There are also disparities in cause of death, with Black women being more likely to suffer from pregnancy-related cardiomyopathy, pulmonary embolism, and hypertensive disorders [9]. In the peripartum period, Black and Hispanic women are at greater risk than white women of both IPV and depression [10-12].

Peripartum health risks can be acute or chronic [13], and confounding symptoms with traditional postpartum experiences can lead to lack of recognition of more severe health risks. For example, while fatigue is a common consequence of postpartum sleep disturbance [14], it may also be an indicator of postpartum depression [15] or cardiomyopathy [16]. A 2018 nine-state maternal mortality review committee demonstrated that an overall lack of knowledge about warning signs and when to receive medical help was one of the most common factors contributing to postpartum maternal mortality [17]. In attempts to more comprehensively reach patients during the postpartum period, guidelines from the American College of Obstetrics and Gynecology (ACOG) have been released suggesting that mHealth apps can help provide supplementary clinical support [18].

Commercial apps communicating about pregnancyrelated health, specifically, are becoming increasingly common $[19,20]$, with healthcare providers endorsing that they play a growing role in maternity care $[18,19]$. Using mHealth apps as a widespread form of supplementary clinical support shows promise in both increasing patient education and in narrowing the knowledge gap in health disparate communities [21, 22]. Most women of reproductive age own smartphones, even among the lowest income brackets. Moreover, there is an almost equal distribution of smartphone use across Black, White, and Latino populations [23]. Approximately $80 \%$ of smartphone owners use their phones to access health information, and Black and Latino smartphone owners are more likely than White smartphone owners to use their phones to research health conditions $[24,25]$. To date, however, there is no existing evaluation of how well commonly-available pregnancy apps explicitly address maternal mortality or morbidity risks or whether the requisite information is presented in a way that makes it accessible to those most at risk.

Currently, the FDA regulates mHealth apps which analyze patient-specific data or give personalized medical guidance but does not regulate apps intended for general patient education [26]. In addition, only a minority of mHealth apps are restricted in access by a prescription from a medical provider or health system [27]. Consequently, many currently-available peripartum mHealth apps have no supervising system ensuring that their published information is accurate and safe for patients.

Even when apps are adequately addressing important health information, their use can be impeded by a failure to tailor them to the specific needs of their audience [28, 29]. Several studies have critically reviewed the content of pregnancy apps [20, 30, 31], with Thomas \& Lupton (2016) finding that pregnancy and other reproductive health apps fail to be inclusive of diverse pregnant people. These findings raise concerns for bias in the language and imagery used in peripartum health apps, which risks further distancing health disparate communities. Increasing the diversity of racial representation in health media, on the other hand, may itself work to reduce social disparities in healthcare [32]. Therefore, in order for mHealth apps to most effectively address pregnancy-related health risks, it is crucial that they be actively inclusive and representative of diverse racial and ethnic groups. 
Additionally, while a peripartum app may offer comprehensive health information and inclusivity, lack of user-centered app design risks ultimately rendering the app ineffective [33]. An mHealth tool's usability- defined by Nielsen (2012) as its ease and enjoyability of use [34] is a multifactorial feature promoted by design elements such as interactivity, functionality, and visual appeal [35]. Failure to incorporate these features in app development can lead to outcomes of low goal-achievement and user attrition [36]. The risk of this is even higher among historically marginalized groups, for whom poor mHealth tool usability has the potential to widen already-existing health disparities [37]. Ultimately, without user-centered design, which prioritizes usability, even peripartum apps with high quality information and strong inclusivity may be inaccessible and ineffective for populations who may benefit from the app's content.

In this analysis, established methods $[38,39]$ of app review were drawn upon to scope the content of commercially available apps for their ability to adequately inform users about behavioral, outpatient, and acute peripartum risk factors. This was done by determining whether they include the requisite maternal health information to address the leading causes of maternal morbidity and mortality as well as other common postpartum risk factors. Each app was then reviewed for inclusivity in language and imagery and for product usability. These three criteria were employed to understand whether commonlyavailable apps are sufficient to provide pregnancy-related health information in a way that is accessible to health disparate communities.

\section{Methods}

\section{Framework}

This study employed the Preferred Reporting Items for Systematic Reviews and Meta-Analyses (PRISMA) standards [40], following similar implementation to other mHealth app reviews of content $[38,39]$.

\section{Search strategy}

The search was limited to the Apple App Store and Google Play, given that 99\% of US smartphone users own either Apple or Android products [41]. To comprehensively capture mHealth apps addressing both the pregnancy and postpartum period, a systematic search was conducted using a combination of key terms, reviewed by both obstetric and family medicine providers. These key terms included:

- Pregnancy

- Fetal development

- Fetal growth

- Labor and Delivery

- Postpartum

\section{- Maternal/maternity}

The search was limited to apps in the Health/Fitness, Medical, and Education categories (as opposed to, e.g. "entertainment") to identify those that may contain clinically relevant content.

\section{Selection criteria}

The review was limited to the top 200 apps identified from each search term applied. Apps that met inclusion criteria and were available in both stores were initially evaluated to identify substantial differences in content and imagery across operating systems. If the app showed consistency, the most recently updated app was included in the review.

\section{Inclusion criteria}

Currently available apps (as of August 2019) targeting pregnant patients or containing content for those who have delivered within the preceding 3 months (those in the "4th trimester") were eligible for review. Apps were required to address education or provide support for physical or mental health needs. For example, apps could be marketed for education, health tracking, medical appointment reminders, or managing stress and anxiety specifically related to pregnancy, childbirth, or early postpartum. To meet those specifications, the inclusion criteria were as follows: (1) apps targeted to pregnant or early postpartum women (up to 3 months postpartum); (2) apps whose primary content was focused on the mother (i.e. not primarily child development or parenting) (2) available through Apple App Store or Google Play; (3) English language; (4) free or paid apps costing less than $\$ 10$ per app (5) apps available in the following Apple App Store categories: Health \& Fitness, and Medical; and (6) apps available in the following Google Play categories: Education, Health \& Fitness, Medical.

\section{Exclusion criteria}

Apps were excluded if they were (1) general parenting apps (2) intended for health care professionals; (3) targeted explicitly towards men or partners of pregnant people (4) classified as e-books by app store description or reviewers (5) entertainment or social networking apps (6) targeting a single specific symptom or condition that might be experienced in the postpartum period (i.e. cognitive behavioral therapy apps for depression) or (7) required a prescription from a medical professional or health system to fully access the app functions. This last criterion was instated to capture only apps that were available to the general public and not limited by an individual's access to formal healthcare. 


\section{Screening process}

After removal of duplicates, the title and store descriptions of all apps identified in an initial search were screened to determine eligibility for full review. Apps that were eligible for full review were downloaded. For the full review, one primary reviewer evaluated the entire set of Android and iOS apps. The apps were then evaluated independently by one of three secondary reviewers, who were randomly assigned a subset of apps to review. If any uncertainties or disagreements were identified in coding, they were reviewed by the entire research team and resolution was achieved by group consensus.

\section{Measures}

\section{Maternal health information}

To comprehensively capture information that may be considered necessary for a peripartum app to serve as a clinical support tool, an a priori coding scheme for the apps' maternal health content was developed based on the primary causes of severe maternal morbidity and mortality and referencing ACOG and CDC guidelines for postpartum care topics [18, 42]. Apps were coded for the presence (or absence) of specific maternal health content and for whether that information was connected to a citation from a professional medical organization or peer-reviewed scientific literature, which was labeled "evidence-based." Qualitative notes were made of inaccuracies in health information. Table 1 provides details on the 30 specific codes for maternal health information. Elements were separated into three categories: Peripartum Behaviors, Peripartum Outpatient Care, and Peripartum Acute Health Risks.

\section{Inclusivity}

To evaluate inclusivity of the apps, each was coded for references to race in the written content and imagery embedded in the app. All references were coded for the presence or absence of race-based stereotyping and the specific instance was documented with an open-ended note. A second rater then reviewed the instance and note and created a binary code for presence/absence of a biased reference. Definitions for all coding can be found in Supplemental Appendix A. To categorize an app as offering racial inclusivity, it was noted whether at least $24 \%$ of app-embedded images displayed non-white presenting individuals. This threshold was chosen to reflect the percentage of the U.S. identifying as a race other than white according to the 2019 US Census estimate [43].

\section{Usability}

The Mobile Application Rating Scale (MARS) was used to assess the usability of the mHealth apps. This scale consists of 4 subscales: engagement, functionality, aesthetics, and information quality. These subscales are
Table 1 Coding scheme for maternal clinical risk information

\begin{tabular}{|c|c|c|}
\hline \multicolumn{3}{|c|}{ Maternal Health Information } \\
\hline $\begin{array}{l}\text { Peripartum } \\
\text { Behaviors } \\
\end{array}$ & $\begin{array}{l}\text { Peripartum Outpatient } \\
\text { Care }\end{array}$ & $\begin{array}{l}\text { Peripartum Acute } \\
\text { Health Risks }\end{array}$ \\
\hline $\begin{array}{l}\text { Breastfeeding/ } \\
\text { Breast Health }\end{array}$ & Contraceptive Options & $\begin{array}{l}\text { Amniotic Fluid } \\
\text { Embolism }\end{array}$ \\
\hline $\begin{array}{l}\text { Diet/Weight } \\
\text { Trajectory }\end{array}$ & Chronic Health Conditions & $\begin{array}{l}\text { Anesthesia } \\
\text { Complications }\end{array}$ \\
\hline Family Planning & Depression & $\begin{array}{l}\text { Cardiovascular/Heart } \\
\text { Disease }\end{array}$ \\
\hline Infant Safe Sleep & Hypertension & $\begin{array}{l}\text { Cerebrovascular } \\
\text { Accident/Stroke }\end{array}$ \\
\hline $\begin{array}{l}\text { Postpartum Infant } \\
\text { Care }\end{array}$ & Intimate Partner Violence & $\begin{array}{l}\text { C-Section } \\
\text { Complications }\end{array}$ \\
\hline $\begin{array}{l}\text { Postpartum Weight } \\
\text { Loss }\end{array}$ & $\begin{array}{l}\text { Medication Use During } \\
\text { Pregnancy }\end{array}$ & Hemorrhage \\
\hline Sexual Activity & $\begin{array}{l}\text { Medication Use During } \\
\text { Breastfeeding }\end{array}$ & Infections/Sepsis \\
\hline Sleep Quality & Postpartum Mental Health & Pulmonary Embolism \\
\hline \multirow[t]{4}{*}{ Smoking } & $\begin{array}{l}\text { Postpartum Physical } \\
\text { Health }\end{array}$ & $\begin{array}{l}\text { Vaginal Birth } \\
\text { Complications }\end{array}$ \\
\hline & $\begin{array}{l}\text { Postpartum Physical/ } \\
\text { Pelvic Exam }\end{array}$ & \\
\hline & Substance Use Disorder & \\
\hline & $\begin{array}{l}\text { Transitioning to Primary } \\
\text { Care }\end{array}$ & \\
\hline
\end{tabular}

averaged to produce a final mean usability score. Two optional separate subscales are provided to assess subjective quality and perceived impact of the app on user knowledge and behaviors. Each item considered within a subscale uses a 5 -point Likert scale $(1=$ Inadequate, $2=$ Poor, 3 = Acceptable, 4 = Good, $5=$ Excellent). MARS scores from only the primary rater were used, as this scale has not been validated to incorporate ratings from multiple users in the same score [35].

To assess relative rates of usage in the general public, the total number of Apple and/or Google Play Store ratings for each app was recorded.

\section{Data analysis}

Descriptive statistics, frequencies, correlations, and independent $t$ tests were used to summarize the search results and evaluation scores assigned to each app. Data analysis was conducted using IBM SPSS 24.0.

\section{Results}

The PRISMA flowchart of the search process can be seen in Fig. 1. None of the 25 applications coded had received FDA approval.

\section{Maternal health content}

Of the 25 applications coded, only one, "What to Expect" addressed each of the 30 medical topics included 


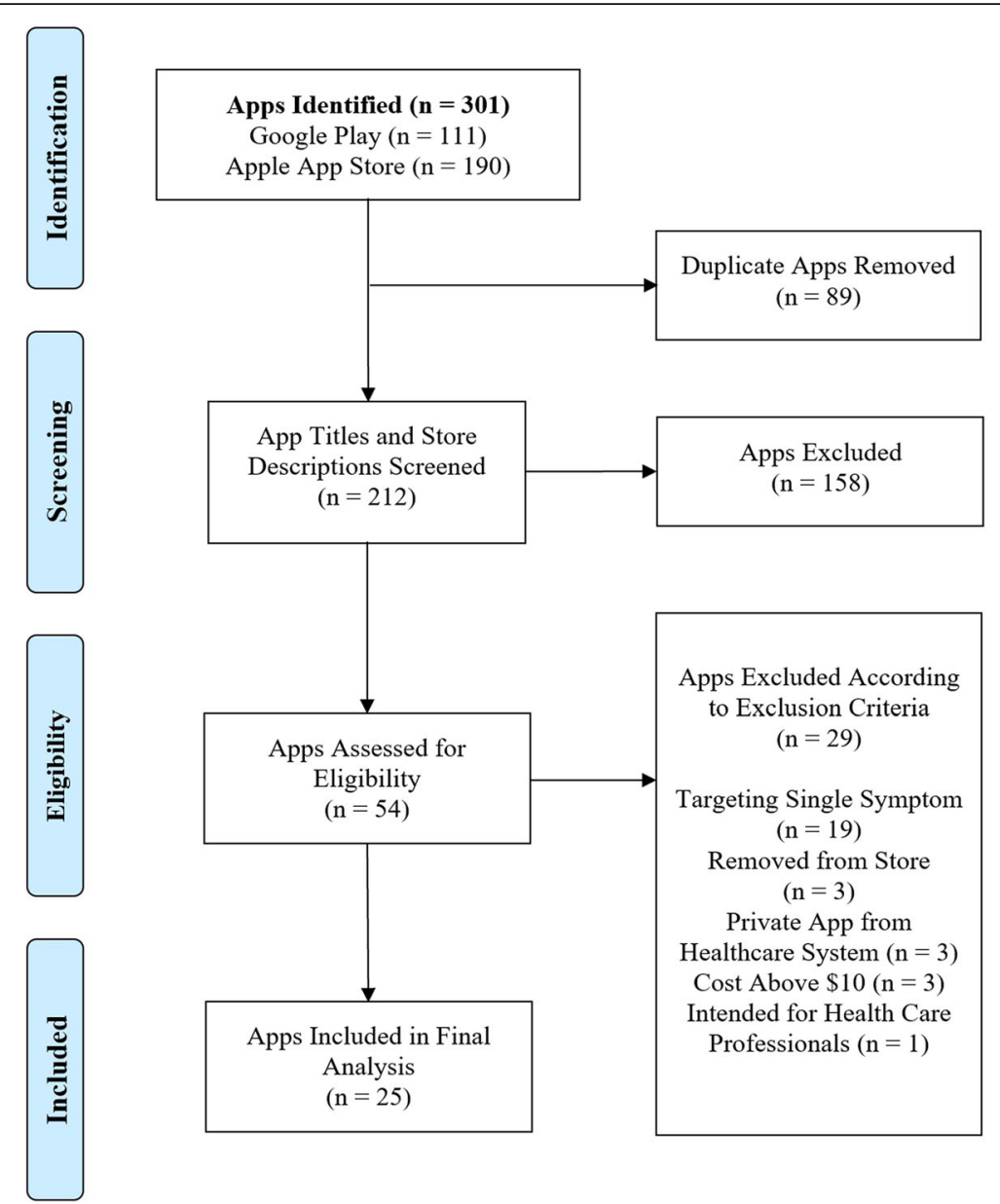

Fig. 1 Preferred Reporting Items for Systematic Reviews and Meta-Analyses flowchart of search process for educational mHealth apps with postpartum maternal morbidity and mortality risk content

in the Maternal Health coding scheme. The median number of elements addressed by each app was 19.5 (65\%), with a range from $4(13.3 \%)$ to 30 (100\%). Apps affiliated with a medical organization (i.e. "Circle by Joseph Health" and "Circle by Swedish") addressed greater than $90 \%$ of the peripartum health topics, whereas the remaining, commercially developed, apps almost universally fell below this threshold. The exceptions to this were the commercially developed "WebMD Pregnancy" and "The Bump," which addressed 29 (96.7\%) and 28 (93.3\%) of the topics, respectively. A significant $(\mathrm{r}(23)=0.643, p=$ $0.001)$ positive correlation was found between the percent of elements addressed in an app and the app's MARS score (Fig. 2). Ten of the 25 apps reviewed (40\%) used evidence-based information. Examples of information addressing a maternal health topic which was not evidencebased include offering guidance on postpartum depression by explaining that mothers who are "feeling down" are likely feeling so because of dissatisfaction with their bodies, suggesting they should "wear flats," and "join an online mom group to beat the postpartum blues."
Peripartum behaviors were the most frequently addressed by apps, with $5 / 9(56 \%)$ addressed by more than $75 \%$ of apps in contrast to $4 / 12(33 \%)$ of peripartum outpatient care topics and $0 / 9(0 \%)$ of peripartum acute health risks. On average, peripartum behaviors were addressed by $70 \%$ of apps, peripartum outpatient care by $59 \%$, and peripartum health risks by $45 \%$. The most widely addressed were breastfeeding/breast health and depression, which were each discussed in 23 apps (92\%) (Fig. 3).

\section{Inclusivity}

Only 32\% (8/24 apps, one app did not contain images) of applications portrayed greater than $24 \%$ of people of color in their imagery. Positive associations were found between the percent of images including people of color and both the MARS score $(\mathrm{r}(22)=0.535, p=0.007)$ and the percent of medical topics addressed $(\mathrm{r}(23)=0.756$, $p<0.001)$. No significant correlation was found between the number of ratings and percent of people of color $(\mathrm{r}$ $(23)=0.271, p=0.20)$. Of the top-10 most-rated apps, only four ("Pregnancy Tracker-BabyCenter," "What to 


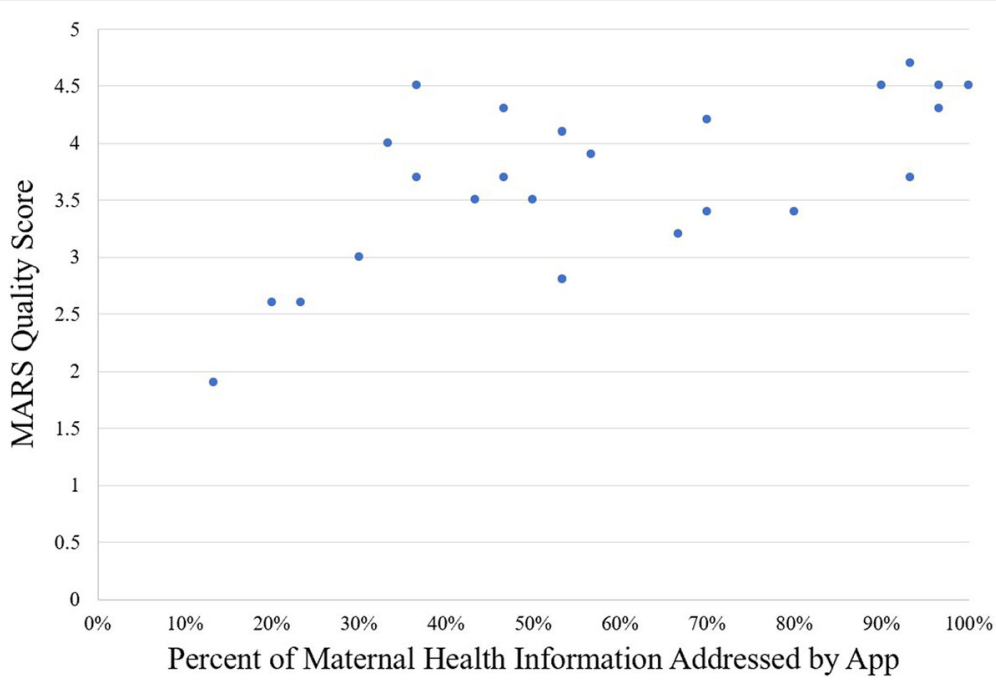

Fig. 2 MARS usability score vs percent of maternal health information addressed by app

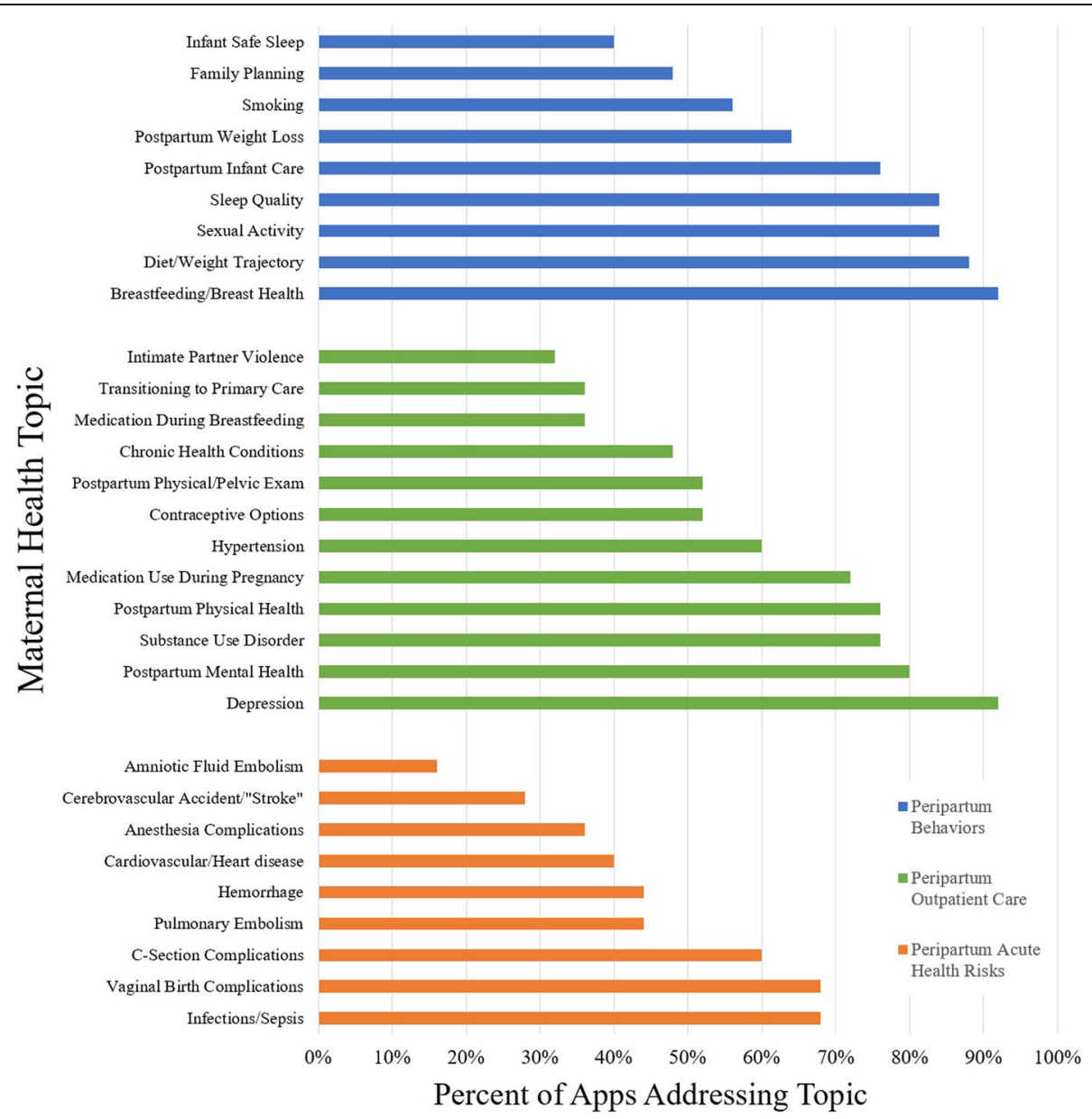

Fig. 3 Percent of mobile applications addressing elements of peripartum behaviors, peripartum outpatient care, and peripartum acute health risks 
Expect," "The Bump," and "Ovia Pregnancy Tracker") reached the $24 \%$ diversity threshold. No race-biased language was noted in any of the apps, but 5 apps (20\%) were noted to have race-biased imagery in the form of depicting women of color exclusively as patients while white individuals were depicted in diverse roles or in majority healthcare worker roles.

\section{Usability}

The average overall MARS usability score for the 25 apps ranged from 1.9 to 4.7, with a mean score of 3.7, representing an "Acceptable" rating. Overall, apps scored high on functionality (mean $=4.3, \mathrm{SD}=0.5$ ) and lower in engagement $($ mean $=3.4, \mathrm{SD}=1.1)$, aesthetics $($ mean $=$ $3.4, \mathrm{SD}=1.1$ ), information (mean $=3.5, \mathrm{SD}=0.9$ ), and overall usability (mean $=3.7, \mathrm{SD}=0.7$ ). The lowestscoring MARS subscale was the optional "Subjective Quality," which is not included in the overall score but takes into account how frequently a user might access the app if relevant to them, whether they would pay for the app, and whether they would recommend it to other users. Subjective quality ratings ranged widely from 1.05.0, $($ mean $=3.0, \mathrm{SD}=1.1)$. "Circle by Swedish" received the highest overall MARS score, 4.7 ("Good"), followed by "What to Expect," "Pregnancy Tracker-BabyCenter," "WebMD Pregnancy," and "Track Pregnancy\&Baby: Preglife," each with a rating of 4.5 ("Good"). None of the apps received an overall score of "Excellent."

No significant correlation was found between the applications' number of store ratings (a proxy for prevalence and popularity) and the proportion of the medical topics the app addressed $(\mathrm{r}(23)=0.252, p=0.224)$ or the MARS score $(\mathrm{r}(23)=0.255, p=0.219)$. While the most-rated app, "Pregnancy Tracker-BabyCenter" (993,267 total ratings), addressed $90.3 \%$ of medical topics and received a MARS score of 4.5 ("Good"), the next-most rated application, "Pregnancy +" (685,310 ratings) addressed only 48.39\% and received a MARS score of only 3.5 ("Acceptable"). "Circle by Swedish," which addressed 96.7\% of medical topics and received the highest MARS score of the apps in this review at 4.7 ("Good"), only received 1216 ratings.

Apps with evidence-based information showed a significantly greater mean percent of maternal health information addressed in the app ( $\mathrm{t}(20)=4.02, p=0.001$ ). These apps also had higher overall MARS scores, ( $t$ $(23)=4.74, p<0.001$ ), with higher ratings on the engagement $(\mathrm{t}(23)=4.06, p<0.001)$, aesthetics $(\mathrm{t}(17)=3.10$, $p=0.007)$, and information sub-scores ( $\mathrm{t}(23)=5.09, p<$ 0.001 ). A significant difference was not observed in the MARS functionality score between the two groups of apps $(\mathrm{t}(21)=1.15, p=0.265)$. There was also no significant difference in the number of store ratings between the apps whose information were and were not evidence-based.

\section{Highest-quality apps}

Four apps met or exceeded all of the following criteria for an acceptable peripartum mHealth application: 1) Shared evidence-based information; 2) addressed greater than or equal to $90 \%$ of maternal health information; 3 ) imagery portrayed at least $24 \%$ people of color; 4) received a MARS score of at least 4 ("Good") in each subcategory of engagement, functionality, aesthetics, and information; 5) did not depict race-biased imagery or language. These apps were "What to Expect," "Pregnancy Tracker - BabyCenter," "Circle by Swedish," and "Circle by Joseph Health."

\section{Discussion}

Updated ACOG guidelines have promoted the use of mobile app-based support in postpartum care [18]. This review has shown that while some peripartum apps provide the medical information, inclusivity, and usability that is optimal for a successful clinical support tool, there is wide variability among the currently available products and many apps fail to meet these standards. The most frequently downloaded apps do not necessarily communicate the most peripartum health information and are not more likely to share evidence-based information. Lack of patient knowledge of warning signs is known to be a leading contributor to postpartum hemorrhage, cardiovascular disease, and cardiomyopathy- three of the leading causes of postpartum morbidity and mortality in the US [17]. The absence of any reference to these specific health risks in over half of the apps reviewed suggests that current offerings are not adequate to provide critical information to those who seek it.

Peripartum behavior and outpatient health topics were addressed more frequently than acute mortality and morbidity risks. For example, breastfeeding health information was provided by almost every app. This highlights an area where the current mobile apps can well serve postpartum women, the majority of whom have difficulty breastfeeding and for whom access to education provides measurable benefits [44, 45]. The content covered may be in response to market demand from app users, given that peripartum women have also expressed desire for additional education regarding postpartum depression, contraception, and physical well-being [46], each of which were addressed in a majority of the apps. However, the lack of evidence-based information in most apps gives pause to recommending them for medical information, exemplified by the app whose mental health discussion only addresses only postpartum blues and recommends only online support groups. While social support online and in person can be protective for postpartum depression $[47,48]$, there is a striking increased risk of mortality and morbidity for women who 
do not receive professional medical and psychological treatment [49]. Connecting patients with apps which minimize or trivialize mental health information may inadvertently put them at greater risk of negative consequences.

The peripartum mHealth apps also tended to lack inclusivity of women of color- and while more inclusive apps were associated with higher usability, they were not more likely to be downloaded by users. One notable shortfall in inclusivity was seen in the rates of maternal health information provided by the apps. Peripartum infections and mental health concerns, conditions that are more prevalent among non-Hispanic white women [17], were addressed by most of the apps, while embolism and cardiomyopathy, which disproportionately affect women of color, were infrequently addressed. A digital divide currently exists in the US, with Black citizens being less likely to have a desktop or laptop and more likely to prefer using mobile phones to seek health information [24]. As apps are a major form of information delivery on smartphones, the subtle bias in providing health information that disproportionately aids white women risks widening the health literacy and therefore peripartum mortality gap. Moreover, a majority of the peripartum apps were shown to lack inclusivity of women of color in their imagery. Black patients are more likely to prefer providers of the same race, $[50,51]$ and culturally appropriate information has been endorsed as a method to increase health equity in the reproductive health of Black women [52]. The subset of apps which represent women of color only as patients also introduces potential damage, as increased racial minority representation in health professions has been shown to reduce health disparities [53]. Providers should be aware that using the currently available commercial apps as clinical support tools may not be inclusive of and effective for women of color.

Even when peripartum apps contain evidence-based, comprehensive health information and are inclusive of marginalized groups, they remain ineffective if they fail to deliver a highly usable mHealth product. In this review there was no correlation between and app's usability and number of app store ratings (and thus by extension the number of users the apps reached). Smartphone users are more likely to download an app they perceive as popular, associating popularity with product quality [54]. In this saturated market of peripartum mHealth tools, consumers may therefore be drawn to download apps of worse informational quality and usability simply because they possess 100 -fold more app store ratings than some higher-quality apps. Importantly, however, actual adoption and employment of mHealth technology is directly related to a tool's usability and perceived usefulness rather than its popularity [55]. In this review, the apps collectively received an overall only
"Acceptable" MARS usability score on subscales of engagement, aesthetics, and information quality. This general lack of user-centered design among peripartum mHealth products and relative popularity of less-usable apps is currently a risk to patients relying on these tools for health information. Access to evidence-based medicine via a mobile app has important potential to improve health behaviors of peripartum women $[31,56]$, but poor usability promotes attrition from mHealth tools and thus diminishes the potential effectiveness of the health information being delivered [36]. In addition, lack of usercentered design supporting mHealth tools makes engagement more challenging and thus further marginalizes populations who already experience a digital divide in healthcare [57]. Therefore, while there is an abundance of commonly available peripartum apps, their overall limited usability risks harm by both reducing effectiveness for users and further widening the gap between health disparate groups.

While mobile apps offer a promising opportunity to improve peripartum care, the current commonly available options are not yet optimal for this purpose. In order for mHealth apps to act as a true complement to maternal healthcare, they must deliver evidence-based and comprehensive information in a manner that is both inclusive of women of color and highly usable [58]. Among a broad market of peripartum mHealth tools, a few products exist which achieve these standards; however, these are vastly outnumbered by apps which exclude important health information, alienate health disparate groups, and fail to provide the user-centered design that is an essential contributor to app efficacy. Healthcare providers should be aware of the dearth of high quality peripartum apps and should consider the components comprising a high-quality tool when discussing mHealth app use with their peripartum patients.

\section{Limitations}

In limiting this review to commercially available products, mHealth apps that have been developed specifically by health systems for their patient populations were unable to be included. While these types of apps will likely share evidence-based information and capture postpartum health risks more comprehensively, they may also have more limited reach. Second, the intent of these apps may not explicitly be to serve as a clinical support tool, though this study surveys whether these tools could fit this purpose. The intent of women using these tools and whether they think of them as clinical support is also not known, and merits exploration in future work. A third limitation to this study, and all studies evaluating diversity of images, is the risk of mis-categorizing images of Black and other women of color. Having multiple reviewers make these judgments aimed to minimize this 
risk; however, it cannot be certain that the researchers' categorization is consistent with how the individual in the image would self-identify. Similar limitations apply to discriminatory text and language. While a subjective measure, the evaluation by multiple reviewers and research group discussion of language attempted to mitigate these limitations. Finally, while the MARS scale is an accepted and validated measure, it was employed only by the researchers and not by the population using the app and, as such, the research team's judgments may not fully reflect those of the population.

\section{Conclusion}

While ACOG has recommended that mHealth apps can provide clinical support to patients during the postpartum period, no comprehensive review has before been done of the information, inclusivity, and usability of the currently available products. This review has found that many popular commercially available peripartum apps do not provide adequate maternal health information, are not inclusive of women of color, and are not optimally usable for patients. Clinicians should be aware of these deficiencies and can use shared decision making to aid patients in finding apps which are accurately informative and without harmful biases or exclusion. Four applications were ultimately found to be acceptable by the criteria of this review, but application content is constantly evolving. While providers may endorse the products highlighted in this review to their patients, general recommendation of apps developed by health systems (e.g. "Circle by Swedish") may be the most appropriate solution to ensuring quality information delivery to patients amidst a dynamic peripartum app landscape.

\section{Abbreviations}

ACOG: American College of Obstetricians and Gynecologists; CDC: Center for Disease Control and Prevention; MARS: Mobile Application Rating Scale; PRIS MA: Preferred Reporting Items for Systematic Reviews and Meta-Analyses

\section{Supplementary Information}

The online version contains supplementary material available at https://doi. org/10.1186/s12884-021-03785-7.

Additional file 1: Supplemental Appendix A. Inclusivity Coding Definitions

\section{Acknowledgements}

We gratefully acknowledge the research assistance of Rebecca Georgiadis, Meghana Akula, Gem Gonzales, and Kelly Nestman.

\section{Authors' contributions}

LT created the research protocol, conducted literature search, conducted app search and screening, evaluated apps based on research protocol, and analyzed and interpreted results. ACV evaluated apps based on research protocol and analyzed and interpreted results. TK created the research protocol, conducted literature search, and analyzed and interpreted results. All authors read and approved the final manuscript.

\section{Funding}

Dr. Krishnamurti's time and the research reported in this publication was supported by the National Center For Advancing Translational Sciences of the National Institutes of Health under Award Number KL2TR001856 and The S\&R Foundation's Kuno Award for Applied Science for the Social Good. The content is solely the responsibility of the authors and does not necessarily represent the official views of the National Institutes of Health.

Availability of data and materials

The datasets used and analyzed during the current study are available on Open Science Framework.

\section{Declarations}

Ethics approval and consent to participate

Not applicable. This study was reviewed by the University of Pittsburgh Institutional Review Board. It was evaluated to have no involvement of human subjects, according to the federal regulations [45 CFR 46.102(e)] and therefore given No Human Subject approval. IRB\# 2003002.

\section{Consent for publication}

Not applicable.

\section{Competing interests}

TK is a co-founder of Naima Health LLC, which develops digital health tools to engage patients in clinical care.

\section{Author details}

'University of Pittsburgh School of Medicine, 3550 Terrace St, Pittsburgh, PA 15213, USA. ²Division of General Internal Medicine, University of Pittsburgh, Pittsburgh, PA 15213, USA.

Received: 26 July 2020 Accepted: 9 April 2021

Published online: 20 April 2021

\section{References}

1. Hoyert DL, Uddin SF, Miniño AM. Evaluation of the pregnancy status checkbox on the identification of maternal deaths; 2020.

2. Creanga AA, Syverson C, Seed K, Callaghan WM. Pregnancy-related mortality in the United States, 2011-2013. Obstet Gynecol. 2017;130(2):366-73. https://doi.org/10.1097/AOG.0000000000002114.

3. Wisner KL, Sit DK, McShea MC, Rizzo DM, Zoretich RA, Hughes $C L$, et al. Onset timing, thoughts of self-harm, and diagnoses in postpartum women with screen-positive depression findings. JAMA Psychiatry. 2013;70(5):490-8. https://doi.org/10.1001/jamapsychiatry.2013.87.

4. Alhusen JL, Ray E, Sharps P, Bullock L. Intimate partner violence during pregnancy: maternal and neonatal outcomes. J Women's Health. 2015;24(1): 100-6. https://doi.org/10.1089/jwh.2014.4872.

5. Creanga AA, Berg CJ, Ko JY, Farr SL, Tong VT, Bruce FC, et al. Maternal mortality and morbidity in the United States: where are we now? J Womens Health. 2014;23(1):3-9. https://doi.org/10.1089/jwh.2013.4617.

6. Howell EA, Egorova N, Balbierz A, Zeitlin J, Hebert PL. Black-white differences in severe maternal morbidity and site of care. Am J Obstet Gynecol. 2016;214(1):122-e1.

7. Vilda D, Wallace M, Dyer L, Harville E, Theall K. Income inequality and racial disparities in pregnancy-related mortality in the US. SSM-Popul Health. 2019; 9:100477. https://doi.org/10.1016/j.ssmph.2019.100477.

8. Petersen EE, Davis NL, Goodman D, Cox S, Mayes N, Johnston E, et al. Vital signs: pregnancy-related deaths, United States, 2011-2015, and strategies for prevention, 13 states, 2013-2017. Morb Mortal Wkly Rep. 2019;68(18): 423-9. https://doi.org/10.15585/mmwr.mm6818e1.

9. Petersen EE, Davis NL, Goodman D, Cox S, Syverson C, Seed K, et al. Racial/ ethnic disparities in pregnancy-related deaths_United States, 2007-2016. Morb Mortal Wkly Rep. 2019;68(35):762-5. https://doi.org/10.15585/mmwr. mm6835a3.

10. Sharps PW, Laughon K, Giangrande SK. Intimate partner violence and the childbearing year: maternal and infant health consequences. Trauma Violence Abuse. 2007;8(2):105-16. https://doi.org/10.1177/1524838007302 594.

11. Thomas JL, Lewis JB, Martinez I, Cunningham SD, Siddique M, Tobin JN, et al. Associations between intimate partner violence profiles and mental 
health among low-income, urban pregnant adolescents. BMC Pregnancy Childbirth. 2019;19(1):120. https://doi.org/10.1186/s12884-019-2256-0.

12. Cheng D, Horon IL. Intimate-partner homicide among pregnant and postpartum women. Obstet Gynecol. 2010;115(6):1181-6. https://doi.org/1 0.1097/AOG.0b013e3181de0194.

13. National Research Council (US) Committee on Population, Reed HE, Koblinsky MA, Mosley WH. The Consequences of Maternal Morbidity and Maternal Mortality: Report of a Workshop. Washington (DC): National Academies Press (US); 2000. APPENDIX A, Definitions

14. Hunter LP, Rychnovsky JD, Yount SM. A selective review of maternal sleep characteristics in the postpartum period. J Obstet Gynecol Neonatal Nurs. 2009;38(1):60-8. https://doi.org/10.1111/j.1552-6909.2008.00309.x.

15. Wilson N, Lee JJ, Bei B. Postpartum fatigue and depression: a systematic review and meta-analysis. J Affect Disord. 2019;246:224-33. https://doi.org/1 0.1016/j.jad.2018.12.032.

16. Hilfiker-Kleiner D, Haghikia A, Nonhoff J, Bauersachs J. Peripartum cardiomyopathy: current management and future perspectives. Eur Heart J. 2015;36(18):1090-7. https://doi.org/10.1093/eurheartj/ehv009.

17. Building U.S. Capacity to Review and Prevent Maternal Deaths. (2018). Report from nine maternal mortality review committees. Retrieved from http://reviewtoaction.org/Report_from_Nine_MMRCs. Accessed 21 May 2020.

18. ACOG Committee Opinion No. 736. Optimizing Postpartum Care. Obstet Gynecol. 2018;131(5):e140-50. https://doi.org/10.1097/AOG.0000000000002 633.

19. Tripp N, Hainey K, Liu A, Poulton A, Peek M, Kim J, et al. An emerging model of maternity care: smartphone, midwife, doctor? Women Birth. 2014; 27(1):64-7. https://doi.org/10.1016/j.wombi.2013.11.001.

20. Hughson JA, Daly JO, Woodward-Kron R, Hajek J, Story D. The rise of pregnancy apps and the implications for culturally and linguistically diverse women: narrative review. JMIR mHealth uHealth. 2018;6(11):e189. https://doi. org/10.2196/mhealth.9119.

21. Liu SY, Fiorentini C, Bailey Z, Huynh M, Mcveigh K, Kaplan D. Structural racism and severe maternal morbidity in New York State. Clinical Medicine Insights. Womens Health. 2019;12:1179562X19854778.

22. ACOG Committee Opinion No. 586. Health disparities in rural women. Obstet Gynecol. 2014;123(2 Pt 1):384-8. https://doi.org/10.1097/01.AOG. 0000443278.06393.d6.

23. Pew Research Center. 2019. Who owns cellphones and smartphones.

24. Perrin A,Pew Research Center. 2019. Smartphones help blacks, Hispanics bridge some - but not all - digital gaps with whites.

25. Anderson-Lewis C, Darville G, Mercado RE, Howell S, Di Maggio S. mHealth technology use and implications in historically underserved and minority populations in the United States: systematic literature review. JMIR mHealth uHealth. 2018;6(6):e128. https://doi.org/10.2196/mhealth.8383.

26. Center for Devices and Radiological Health. Examples of MMAs That Are NOT Medical Devices. U.S. Food and Drug Administration. FDA; [cited 2021 Mar 9]. Available from: https//unw.fda.gov/medical-devices/device-software-functions-including-mobilemedical-applications/examples-mobile-apps-are-not-medical-devices. Accessed 6 Mar 2021.

27. Kao CK, Liebovitz DM. Consumer mobile health apps: current state, barriers, and future directions. PMR. 2017;9(5):S106-15. https://doi.org/10.1016/j. pmri.2017.02.018.

28. Breton ER, Fuemmeler BF, Abroms LC. Weight loss-there is an app for that! But does it adhere to evidence-informed practices? Transl Behav Med. 2011; 1(4):523-9. https://doi.org/10.1007/s13142-011-0076-5.

29. West JH, Hall PC, Hanson CL, Barnes MD, Giraud-Carrier C, Barrett J. There's an app for that: content analysis of paid health and fitness apps. J Med Internet Res. 2012;14(3):e72. https://doi.org/10.2196/jmir.1977.

30. Thomas GM, Lupton D. Threats and thrills: pregnancy apps, risk and consumption. Health Risk Soc. 2016;17(7-8):495-509. https://doi.org/10.1 080/13698575.2015.1127333.

31. Overdijkink SB, Velu AV, Rosman AN, Van Beukering MD, Kok M, SteegersTheunissen RP. The usability and effectiveness of mobile health technology-based lifestyle and medical intervention apps supporting health care during pregnancy: systematic review. JMIR mHealth uHealth. 2018;6(4): e109. https://doi.org/10.2196/mhealth.8834.

32. Myers T, Richardson F, Chung JE. Racial and ethnic makeup in hospital's social media and online platforms: visual representation of diversity in images and videos of Washington, DC hospitals. J Health Commun. 2019; 24(5):482-91. https://doi.org/10.1080/10810730.2019.1617807.
33. Torous J, Nicholas J, Larsen ME, Firth J, Christensen H. Clinical review of user engagement with mental health smartphone apps: evidence, theory and improvements. Evid Based Mental Health. 2018;21(3):116-9. https://doi.org/1 0.1136/eb-2018-102891.

34. Richardson B, Dol J, Rutledge K, Monaghan J, Orovec A, Howie K, et al. Evaluation of mobile apps targeted to parents of infants in the neonatal intensive care unit: systematic app review. JMIR mHealth uHealth. 2019;7(4): e11620. https://doi.org/10.2196/11620.

35. Stoyanov SR, Hides L, Kavanagh DJ, Zelenko O, Tjondronegoro D, Mani M. Mobile app rating scale: a new tool for assessing the quality of health mobile apps. JMIR mHealth uHealth. 2015;3(1):e27. https://doi.org/10.2196/mhealth.3422.

36. Inal $Y$, Wake JD, Guribye F, Nordgreen $T$. Usability evaluations of mobile mental health technologies: systematic review. J Med Internet Res. 2020; 22(1):e15337. https://doi.org/10.2196/15337.

37. Miller DP Jr, Weaver KE, Case LD, Babcock D, Lawler D, Denizard-Thompson N, et al. Usability of a novel mobile health iPad app by vulnerable populations. JMIR mHealth uHealth. 2017;5(4):e43. https://doi.org/10.2196/mhealth.7268.

38. Knitza J, Tascilar K, Messner EM, Meyer M, Vossen D, Pulla A, et al. German mobile apps in rheumatology: review and analysis using the mobile application rating scale (MARs). JMIR mHealth uHealth. 2019;7(8):e14991. https://doi.org/10.2196/14991.

39. Creber RM, Maurer MS, Reading M, Hiraldo G, Hickey KT, Iribarren S. Review and analysis of existing Mobile phone apps to support heart failure symptom monitoring and self-care management using the Mobile application rating scale (MARS). JMIR mHealth uHealth. 2016;4(2):e74. https://doi.org/10.2196/mhealth.5882.

40. Moher D, Liberati A, Tetzlaff J, Altman DG, Prisma Group. Preferred reporting items for systematic reviews and meta-analyses: the PRISMA statement. PLoS Med. 2009;6(7):e1000097.

41. Subscriber share held by smartphone operating systems in the United States from 2012 to 2020. In Statista - The Statistics Portal. August 2020. Available from https://www.statista.com/statistics/266572/market-share-heldby-smartphone-platforms-in-the-united-states/. Accessed 12 Dec 2020.

42. Centers for Disease Control and Prevention. After the Baby Arrives. https:// www.cdc.gov/pregnancy/after.html. Accessed 1 Aug 2019.

43. U.S. Census Bureau. U.S. Census Bureau QuickFacts. In: American Community Survey 5-year estimates; 2019. Retrieved from https://www.census.gov/ quickfacts/fact/table/US/PST045219.

44. Duckett L, Henly SJ, Garvis M, Weiss JR, Humenick SS. Predicting breastfeeding duration during the postpartum hospitalization. West J Nurs Res. 1993;15(2):177-98. https://doi.org/10.1177/019394599301500204.

45. Wagner EA, Chantry CJ, Dewey KG, Nommsen-Rivers LA. Breastfeeding concerns at 3 and 7 days postpartum and feeding status at 2 months. Pediatrics. 2013;132(4):e865-75. https://doi.org/10.1542/peds.2013-0724.

46. Tully KP, Stuebe AM, Verbiest SB. The fourth trimester: a critical transition period with unmet maternal health needs. Am J Obstet Gynecol. 2017; 217(1):37-41. https://doi.org/10.1016/j.ajog.2017.03.032.

47. Kim TH, Connolly JA, Tamim H. The effect of social support around pregnancy on postpartum depression among Canadian teen mothers and adult mothers in the maternity experiences survey. BMC Pregnancy Childbirth. 2014;14(1):162. https://doi.org/10.1186/1471-2393-14-162.

48. Evans M, Donelle L, Hume-Loveland L. Social support and online postpartum depression discussion groups: a content analysis. Patient Educ Couns. 2012;87(3):405-10. https://doi.org/10.1016/j.pec.2011.09.011.

49. Cuijpers P, Brännmark JG, van Straten A. Psychological treatment of postpartum depression: a meta-analysis. J Clin Psychol. 2008;64(1):103-18. https://doi.org/10.1002/jclp.20432.

50. Malat J, Hamilton MA. Preference for same-race health care providers and perceptions of interpersonal discrimination in health care. J Health Soc Behav. 2006;47(2):173-87. https://doi.org/10.1177/002214650604700206.

51. Chen FM, Fryer GE, Phillips RL, Wilson E, Pathman DE. Patients' beliefs about racism, preferences for physician race, and satisfaction with care. Ann Fam Med. 2005;3(2):138-43. https://doi.org/10.1370/afm.282.

52. Prather C, Fuller TR, Jeffries WL IV, Marshall K, Howell AV, Belyue-Umole A, et al. Racism, African American women, and their sexual and reproductive health: a review of historical and contemporary evidence and implications for health equity. Health Equity. 2018;2(1):249-59. https://doi.org/10.1089/ heq.2017.0045.

53. Fleming R, Berkowitz B, Cheadle AD. Increasing minority representation in the health professions. J Sch Nurs. 2005;21(1):31-9. https://doi.org/10.1177/1 0598405050210010801. 
54. Gu J, Xu YC, Xu H, Zhang C, Ling H. Privacy concerns for mobile app download: an elaboration likelihood model perspective. Decis Support Syst. 2017;94:19-28. https://doi.org/10.1016/j.dss.2016.10.002.

55. Zapata BC, Fernández-Alemán JL, Idri A, Toval A. Empirical studies on usability of mHealth apps: a systematic literature review. J Med Syst. 2015; 39(2):1. https://doi.org/10.1007/s10916-014-0182-2.

56. Vartanian K, Rinaldi JB, Pieper K, Jellison T. Effect of a health system sponsored Mobile app on perinatal health behaviors [13E]. Obstet Gynecol. 2020;135:52S-3S. https://doi.org/10.1097/01.AOG.0000663584.13575.df.

57. Sarkar U, Gourley GI, Lyles CR, Tieu L, Clarity C, Newmark L, et al. Usability of commercially available mobile applications for diverse patients. J Gen Intern Med. 2016;31(12):1417-26. https://doi.org/10.1007/s1 1606-016-3771-6.

58. Krishnamurti T, Davis AL, Wong-Parodi G, Fischhoff B, Sadovsky Y, Simhan $\mathrm{HN}$. Development and testing of the Myhealthypregnancy app: a behavioral decision research-based tool for assessing and communicating pregnancy risk. JMIR mHealth uHealth. 2017;5(4):e42. https://doi.org/10.2196/mhealth. 7036.

\section{Publisher's Note}

Springer Nature remains neutral with regard to jurisdictional claims in published maps and institutional affiliations.

Ready to submit your research? Choose BMC and benefit from:

- fast, convenient online submission

- thorough peer review by experienced researchers in your field

- rapid publication on acceptance

- support for research data, including large and complex data types

- gold Open Access which fosters wider collaboration and increased citations

- maximum visibility for your research: over $100 \mathrm{M}$ website views per year

At BMC, research is always in progress.

Learn more biomedcentral.com/submissions 